\title{
Multi-objectives evaluation framework: A comparative study on the relationship between urban form and key environmental performance indicators in Tianjin Eco-city
}

\author{
G.P. Raharjo $^{\text {a }}$, C.K. Heng ${ }^{\text {a }}$, J. Zhang ${ }^{\text {b }}$, X.F. Sun ${ }^{\text {c }}$ Y.H. Chao ${ }^{\text {a }}$, M.Q. Shao ${ }^{\text {a }}$ \\ ${ }^{a}$ Centre for Sustainable Asian Cities - School of Design \& Environment, National University of Singapore, \\ ${ }^{b}$ Solar Energy Research Institute of Singapore, National University of Singapore, ${ }^{c}$ Construction Bureau \\ China-Singapore Tianjin Eco-City
}

\begin{abstract}
This study is a continuity of the previous studies done at the Centre for Sustainable Asian Cities in discussing the relationship between density, urban form, urban environmental performance, urban sustainability, and the relationship between these domains. A quantitative framework to evaluate the key environmental factors affecting physiological \& psychological comfort and building energy consumption was developed and demonstrated. The framework involves simulations on façade Vertical Daylight Factor, façade and envelope Sky Exposure Factor, urban surface Sky View Factor, and envelope annual cumulative irradiance at precinct scale in the context of the Tianjin Eco-city. The results highlight the presence of strong and significant correlations between urban form characteristics and key environmental performance indicators. These correlations are useful to inform the primary and secondary planning \& design parameters that may affect each performance area and to understand the differences in the impact of each design parameters on various performance areas.
\end{abstract}
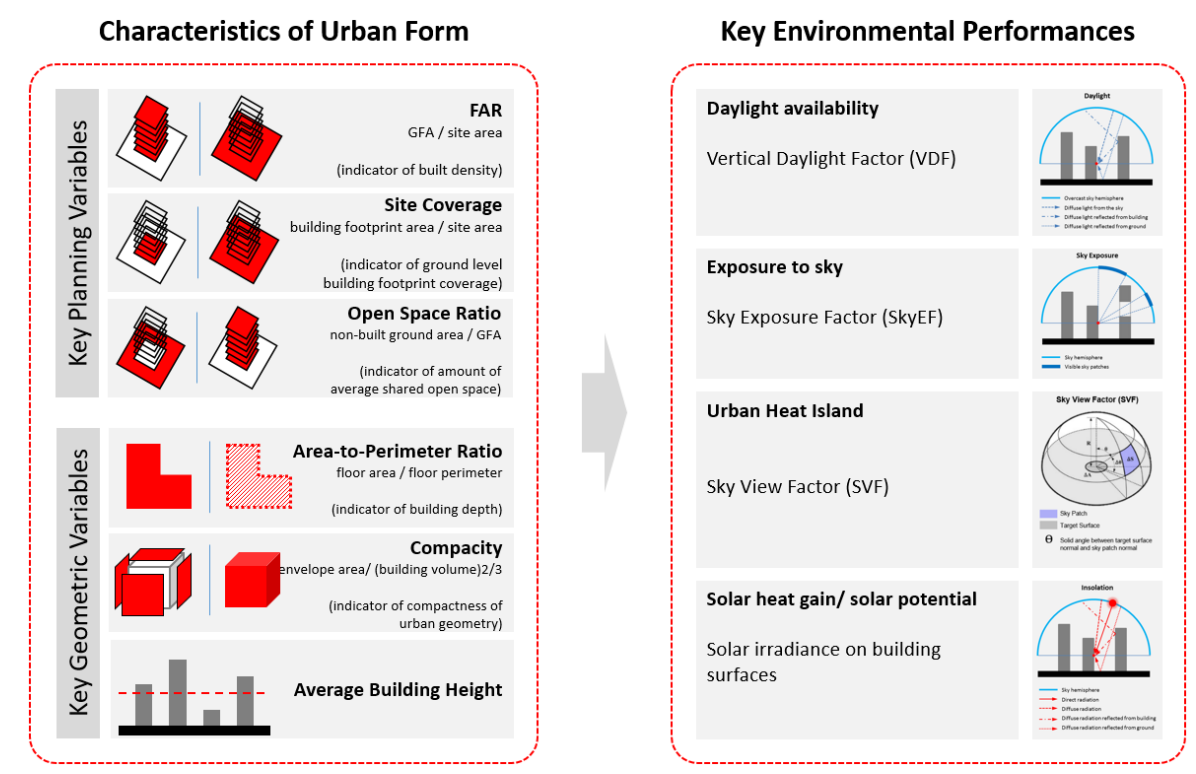

Figure 1. Relationship between design \& planning variables and key environmental performance indicators explored in this study

Keywords: Meso-scale study, multi-objectives evaluation workflow, key environmental performance indicators, sky exposure factor 
G.P. Raharjo, Multi-objectives optimization framework: A comparative study on the relationship between urban block typologies and key environmental performance indicators in Tianjin Eco-city

\section{INTRODUCTION}

The advantages and disadvantages of high density urban development evoke on-going debate. High density urban development is often associated with poor living condition due to the limitation of urban infrastructures supporting water, energy, food, sewage \& waste disposal system, transports, social infrastructure, as well as work opportunities (Vale \& Vale, 2010). However, in the situation where the resources are limited to support ever-growing population, high density urban development is theorized to be the ideal form according to the environmental sustainability point of view (Churchman 1999). Therefore, increasing built density is an objective from the perspective of urban planning at the city scale (Jabareen, 2006). To reconcile the dichotomy of high density urban development, the optimal urban form and model has been continuously searched (Newman, 1992; Gordon, 1989). However, due to the complexity in defining the objectives constituting the sustainable urban development, a consensus on the ideal urban development model is yet to be found (Martine, 2008).

Previous studies at the Centre for Sustainable Asian Cities (Heng et al., 2017, 2016, 2014, Zhang et al., 2013, 2012a, 2010, Hii et al., 2011) attempted to explore possible objectives characterising the sustainable urban development. Urban environmental sustainability was approached from the building energy consumption aspect because its implication on energy conservation is evident as building energy consumption contributes a large share of total global energy consumption (WBCSD, 2009). This is done through several quantitative investigations on the relationship between characteristic of urban configuration and the key environmental performance indicators. The current project aims to refine and expand the evaluation framework developed from previous studies by improving the methodology and exploring alternative combinations of the relevant variables to investigate the relationship between urban form and key environmental performances. With a better understanding of this relationship, it is possible to evaluate the current urban developments and optimise future urban developments in favour of effective building energy consumption leading to evidence-based planning for environmental sustainability.

It is instructive to select the Tianjin Eco-city (TEC) for the application of the methodology developed in this study because TEC is conceptualised at the master planning phase to take environmental performance into planning \& design consideration, and certain performance targets are enforced for precinct-level developments. Evaluating the existing TEC precincts and to compare their performance to the precincts from other contexts hopefully, shedding light on the characteristics of urban form that yield superior environmental performances for Tianjin Eco-city's climatic condition.

\section{LITERATURE REVIEW ON ENVIRONMENTAL PERFORMANCE MEASUREMENTS}

Investigation on the environmental performances of urban environments pertaining building energy consumption is multifaceted. It requires delineation of the relevant and significant environmental factors influencing building energy use. From the previous studies, it was found that daylight availability and solar radiation are the two key environmental factors that have significant impact on human comfort and building energy consumption shown in Table 1 (Heng et al. 2017, 2016, 2014, Zhang et al., 2013, 2012a).

Table 1. Key environmental variables and their implications.

\begin{tabular}{|c|c|c|c|c|c|}
\hline \multicolumn{2}{|c|}{ Implications } & \multicolumn{3}{c|}{ Key Environmental Variables } \\
\cline { 3 - 5 } \multicolumn{2}{|c|}{} & Daylight & Sky Exposure & Solar Irradiance & Sky View Factor \\
\hline $\begin{array}{c}\text { Physiological } \\
\text { Comfort }\end{array}$ & Thermal & & & & \\
\cline { 2 - 5 } & Visual & & & & \\
\hline \multicolumn{2}{|c|}{ Psychological Well-being } & & & & \\
\hline Building Energy Consumption & & & & \\
\hline Urban Heat Island Phenomenon & & & & \\
\hline
\end{tabular}

direct implication

indirect implication

In this study, the two key environmental performances are investigated through simulations on four key performance indicators, namely: Vertical daylight factor, Sky Exposure Factor, Sky View Factor; and Annual Solar Irradiance.

Vertical Daylight Factor (VDF) measures daylight availability which is the ratio of daylight level of a given point on vertical surface to that of an unobstructed point on horizontal surface under the CIE standard overcast 
sky condition, and it is regarded as an indicator of daylight potential under the worst case scenario $(\mathrm{Ng} 2003$, Ng 2009, Zhang et al. 2012a).

Sky Exposure Factor (SkyEF) measures the degree of exposure to visible sky which is the ratio of solid angle subtended by visible sky patches from a given view point on building façade or ground surface to that of the entire unobstructed sky hemisphere (Zhang et al. 2012b, Heng et al. 2017).

Sky View Factor ( $S V F$ ) measures the ratio of the visible sky patch from a specific point to the unobstructed sky dome, and this factor has been suggested to have implication on urban heat island, daylight availability and solar radiation exchange in urban canyons. (Brown et al. 2001, Cheng 2006, Fuehrer 2000, Harman 2004, Oke 1981, Oke 1988, Ratti 2003, Svenssoon 2004, Zhang 2010).

Cumulative annual solar irradiance measures the incident solar radiation which has significant implication on building energy consumption, the urban heat island effect and building occupants' thermal comfort. On the other hand, incident solar radiation on building envelope can also be used to evaluate the potential of solar energy harvesting. For this study, a cumulative sky was constructed from local weather file in which the hourly solar radiation values were aggregated so as to obtain the annual radiation incident from just one simulation (Robinson \& Stone, 2004, Heng et al. 2017).

The selection of the key performance indicators regards the degree of operationality i.e. physical consistency, spatial consistency, measurability, legibility, and comparability, and the environmental aspect measured should not be redundant (Philip 2014). These indicators are to be normalised according to their respective Gross Floor Area (GFA Normalised Performance Indicator - GN in short) to reflect the effects of urban form characteristics across different densities (Zhang 2012a).

\section{METHODOLOGY}

\subsection{Scale of analysis}

The basic unit of analysis used in this study is urban blocks surrounded by external roads, which is the basic component of the urban fabric and urban planning (Zhang et al. 2012). This resolution allows us to measure the quality of the micro-environment including the significant implication of the configuration of its immediate surrounding on the environmental performance, which is the condition observed in urban contexts.

\subsection{Scope of analysis}

The characteristic of urban form is described in two categories of parameters (Figure 1): 1) Planning parameters - refers to variables related to planning \& regulation that include: Floor-to-Area Ratio (FAR indicator of built density), Site coverage (indicator of ground level building footprint coverage), Open Space Ratio (OSR - indicator of amount of average shared ground-level unbuilt area), and 2) Geometric parameters - refers to variables related to building forms that include: Area-to-perimeter ratio (APR - indicator of building depth), compacity (indicator of compactness of urban geometry), and average building height (indicator of relative height of an urban precinct). As for the key environmental performances, they are represented by four GFA-normalised indicators elaborated in the previous section

At the precinct scale, the urban forms are represented by building massings constructed from the extrusions of their footprints in their original height, orientation, and layout (Figure 2). Architectural details are not modelled because their impact on environmental performance is marginal compared to the general precinct configuration. Similarly, vegetation and landscaping elements are not modelled because their impact are not consistent throughout seasons (Philip, 2014). In addition, the 3-by-3 grid method proposed by Zhang (2013) to represent homogenous urban context was not adopted due to wide cross-section of the major roads $(30-46 \mathrm{~m})$ separating each precinct in Tianjin Eco-city. The impact of neighbouring precincts across the surrounding roads on the environmental performance is marginal.

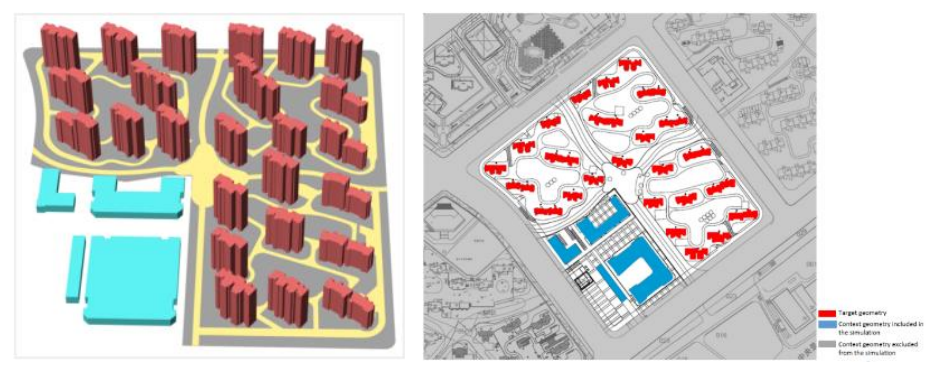

Figure 2. Diagram showing the entities modelled for simulation process. 
G.P. Raharjo, Multi-objectives optimization framework: A comparative study on the relationship between urban block typologies and key environmental performance indicators in Tianjin Eco-city

The selection of the target geometry for simulation is crucial in order to render the simulation analysis to be useful and representative of the environmental performances investigated. The simulation tools and algorithms used are designed for general daylight and solar irradiance analysis. Therefore, there was a need to customise several parameters to fit the purpose of the current study. Façade analysis is for environmental performance analyses related to daylight availability and visual comfort (Façade VDF \& Façade SkyEF), building envelope analysis is for environmental performance analyses related to openness to the sky \& solar radiation (Envelope SkyEF \& Annual Irradiance), and urban surfaces analyses for environmental performance analysis related to urban heat island effect (Urban surface SVF). The 3D models of the case studies are to be deconstructed according to different planes to accommodate the definition of the respective environmental performance analysis (Figure 3).

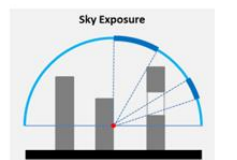
Perceived openness, daylight heat gain, building energy heat gain, building energy
consumption, visual comfort

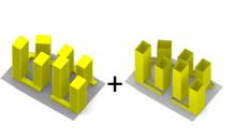

$\begin{array}{cc}\begin{array}{c}\text { Building } \\ \text { Bnvelope }\end{array} & \begin{array}{c}\text { Building } \\ \text { facade }\end{array}\end{array}$

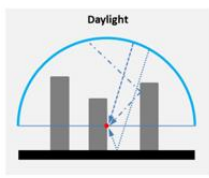

Davlight availability, visual comfort, solar radiation he gain, building ener
consumption

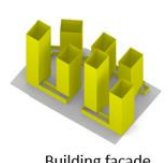

Building facade

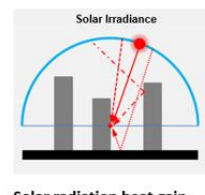

Solar radiation heat gain building energ consumption, Urban Heat

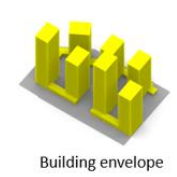

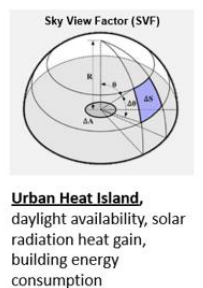

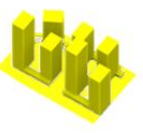

Urban surface

Figure 3. Diagram illustrating the key environmental indicators and their respective target geometries.

\subsection{Integrated workflow}

For the purpose of this study, a customised workflow on McNeels Rhinoceros 3D + Grasshopper ${ }^{1}$ software was created to integrate the 3D modelling of buildings, calculation of geometric and planning variables, and running the performance simulations seamlessly (Table 2). For the purpose of this simulation, the Tianjin city weather data derived from Chinese Standard Weather Data (CSWD) from China Meteorological Bureau in .ewp file format was used as local weather data input for solar irradiance simulation and sky view factor simulation.

Table 2. Diagram showing the simulation workflow ${ }^{2,3}$.

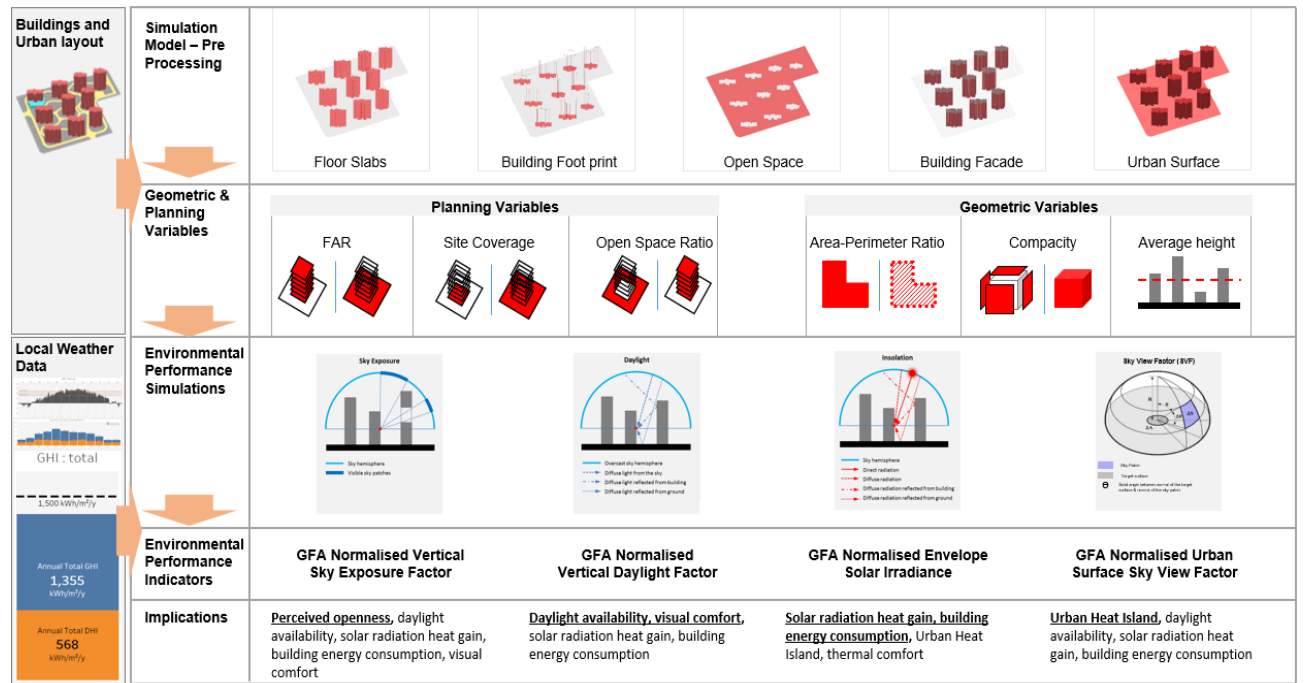

\footnotetext{
${ }^{1}$ Rhinoceros 3D is A NURBS based modelling software (https://www.rhino3d.com). Grasshopper is a visual programming extension of Rhinoceros $3 D$

2 Daylight, Sky Exposure, Solar Irradiance - Source: Heng, C. K., Malone-Lee, L. C., Zhang, Ji., Hii, Daniel, Ibrahim, N. (2014) Sustainable Housing Typologies - Planning and Development for Sustainable High Density Living: High Density Threshold Studies, A research report submitted to the Ministry of National Development.

${ }^{3}$ Sky View Factor - Source: Oke, T.R. (1981) Canyon geometry and the nocturnal urban heat island: comparison of scale model and field observations. Journal of Climatology. 1(3): p. 237-254.
} 
G.P. Raharjo, Multi-objectives optimization framework: A comparative study on the relationship between urban block typologies and key environmental performance indicators in Tianjin Eco-city

\subsection{Case study approach}

Case study was chosen as the approach for this investigation. Following the categorisation of urban form based on the observable layout present in Tianjin city (Wang, 2016) and China standard building typologies ${ }^{4}$, the selection matrix was constructed (Table 3 ). The case studies were selected to cover the matrix as much as possible. 16 case studies were selected from Tianjin Eco-city. 8 cases from Tianjin city were selected as benchmark cases to contrast the impact of different planning regulations resulting in different planning parameters. In addition, 6 selected TEC cases were modified to test the performance of their existing configuration for higher FAR by increasing the floor area upward. In total, 30 cases were studied to investigate the relative performance of urban form of different characteristics on respective key environmental performance indicators.

Table 3. On the left: case study selection criteria; on the right: case study distribution matrix.
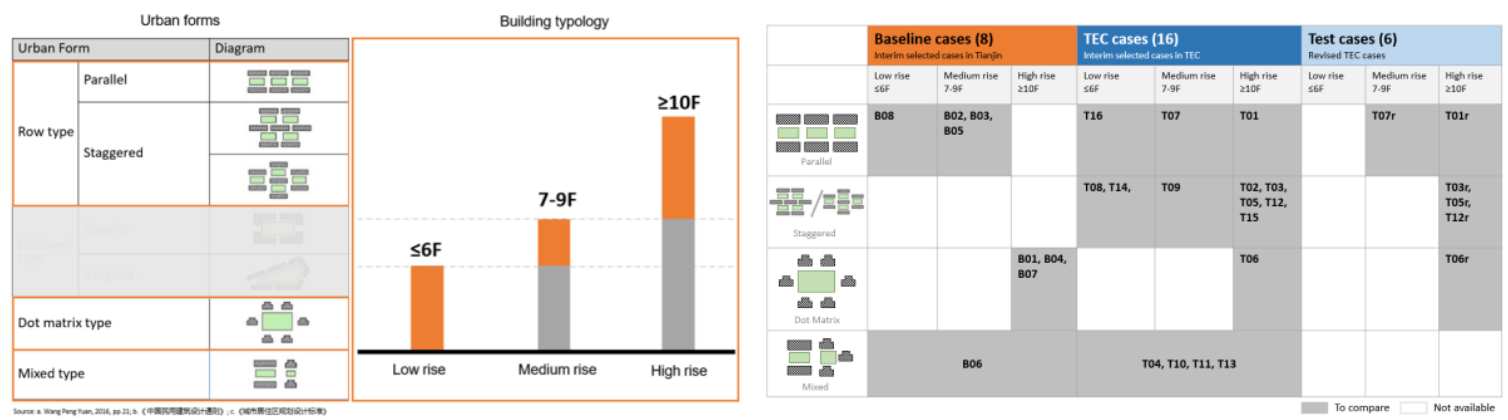

Table 4. Planning and geometric properties of the 30 case studies.

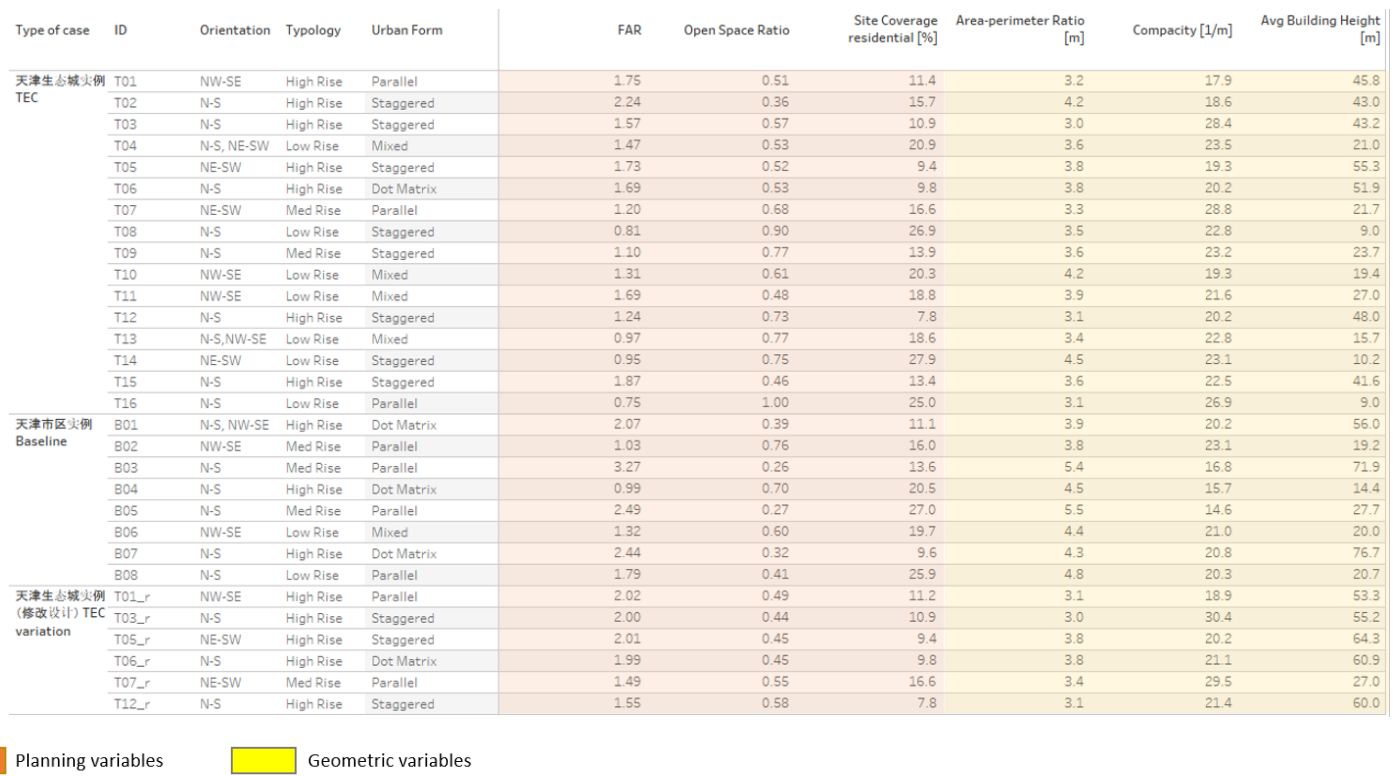

\section{RESULT \& ANALYSIS}

In order to understand the impact of urban form characteristics on key environmental performances, bi-variate regression analysis was done for respective planning and geometric parameters as the independent variables and the performance indicators representing daylight, solar radiation, sky exposure, and solar heat gain/ solar potential performance as the dependent variables. The results show the presence of strong and significant correlations between planning \& geometric characteristic and key performance indicators, shown in (Table 5) where the magnitude and the direction of the correlations are highlighted.

\footnotetext{
4 《中国民用建筑设计通则》 and 《城市居住区规划设计标准》: Low rise (=< 6 storeys), Medium rise (7 to 9), and High Rise (>= 10 storeys)
} 
G.P. Raharjo, Multi-objectives optimization framework: A comparative study on the relationship between urban block typologies and key environmental performance indicators in Tianjin Eco-city

Table 5. Correlations between urban form characteristics and key environmental performance indicators.

\begin{tabular}{|l|c|c|c|c|c|c|c|}
\hline & $\begin{array}{c}\text { Floor- } \\
\text { area Ratio } \\
\text { (FAR) }\end{array}$ & $\begin{array}{c}\text { Area- } \\
\text { perimeter } \\
\text { Ratio } \\
\text { (APR) }\end{array}$ & $\begin{array}{c}\text { Avg } \\
\text { Building } \\
\text { Height }\end{array}$ & $\begin{array}{c}\text { Open Space } \\
\text { Ratio (OSR) }\end{array}$ & $\begin{array}{c}\text { Residential } \\
\text { Site } \\
\text { Coverage }\end{array}$ & $\begin{array}{c}\text { Roof-to- } \\
\text { Compacity }\end{array}$ & $\begin{array}{c}\text { Roof-to- } \\
\text { floor Area } \\
\text { Ratio } \\
\text { (RfAR) }\end{array}$ \\
$\begin{array}{l}\text { Area Ratio } \\
\text { (ReAR) }\end{array}$ \\
GDF Façade
\end{tabular}

The correlations between planning \& geometry variables and key environmental performance indicators can be construed in two ways:

Construing the relationship with respect to planning \& geometric variables informs the direction and the significance of the changes on the respective variables correlated with the key environmental performance indicators e.g. FAR has strong and significant inverse correlation with GN Envelope SkyEF and GN Urban surface SVF; therefore an increase of FAR may likely be accompanied with a decrease primarily in these two key indicators.

Construing the relationship with respect to key environmental performance indicators informs the planning \& geometric variables that have relatively stronger relationship than the others e.g. GN Façade VDF is strongly and significantly correlated with APR, OSR, and Compacity; therefore any changes on these variables are more likely to be accompanied with changes in GN Façade VDF than the other planning \& geometry variables.

\section{DISCUSSION \& CONCLUSION}

The research findings are useful to help policy-makers to prioritize planning and design related decision such as to determine the primary and secondary design parameters that may affect each performance area and to understand the differences of their impact. It is to note that the conclusion of this study is derived from the 30 case studies selected in the study. Thus, the correlation values might change with the addition of data points. The more data points, the more validated are the findings.

Albeit the specificity of this study, the methodology and the approaches on evaluating key environmental performances at meso-scale can be replicated and appropriated for other contexts due to the modular design of the approach. It is hoped that the possibilities and limitations of this method of inquiry are successfully demonstrated and illustrated.

For future study, it is also useful to investigate the relationship between urban form characteristics and building energy use intensity through building energy simulation to observe which of the factors that are correlated directly. Otherwise, this relationship can only be extrapolated from the performance on the selected key environmental indicators.

\section{ACKNOWLEDGEMENT}

This research project (WBS: R-294-000-071-490) is part of the ongoing collaborative project with Tianjin University and funded by the Ministry of National Development of Singapore (MND) and conducted at the Centre for Sustainable Asian Cities, School of Design and Environment, National University of Singapore. We acknowledge the support from the Ministry and the collaborating government agencies which include the Building and Construction Authority (BCA), Sino-Singapore Tianjin Eco-City Administrative Committee (ECAC).

\section{REFERENCES}

Brown, M. J., et al. (2001). Comparison of Methodologies for Computing Sky View Factor in Urban Environments. International Symposium on Environmental Hydraulics. Los Alamos, New Mexico, USA, Los Alamos National Laboratory. 
Cheng V., Steemers, K, Montavon, M \& Compagnon, R (2006). Urban Form, Density and Solar Potential', 23rd Conference on Passive and Low Energy Architecture, Geneva, Switzerland.

Churchman, A. (1999). Disentangling the Concept of Density. Journal of Planning Literature, 13 (4), 389-441.

Fuehrer, PL \& Friehe, CA (2000). A Physically-Based Scheme for The Urban Energy Budget In Atmospheric Models', Boundary-Layer Meteorology, vol. 90, pp. 241-295.

Harman, IN, Best, MJ, \& Belcher, SE (2004). 'Radiative Exchange in an Urban Street Canyon', BoundaryLayer Meteorology, vol. 110, pp. 301-316.

Hii, D.J.C., Heng, C.K., Malone-Lee, L. C., \& Zhang, J., Ibrahim, N., Huang, Y.C., \& Janssen, P. (2011). Solar Radiation Performance Evaluation for High-density Urban Forms in the Tropical Context Proceedings of the Building Simulation International Conference. Sydney, Australia

Heng, C.K., Malone-Lee, L.C., \& Zhang, J. (2014). Sustainable Housing Typologies Planning and Development for Sustainable High Density Living: High Density Threshold Studies, A research report submitted to the Ministry of National Development Singapore

Heng, C.K., Malone-Lee, L.C., \& Zhang, J. (2016). Pursuing Sustainability: Density and Design Matter. Innovation - The Singapore Magazine of Research, Technology and Education, 15 (1), 4-9.

Heng, C. K., Malone-Lee, L. C., \& Zhang, J. (2017). Relationship between Density, Urban Form and Environmental Performance. In J. H. Bay \& S. Lehmann (Eds.), Growing Compact: Urban Form, Density and Sustainability: Routledge.

Jabareen, Y. R. (2006). Sustainable Urban Forms: Their Typologies, Models, and Concepts. Journal of Planning Education and Research, 26(1), 15. doi:10.1177/0739456X05285119

$\mathrm{Ng}$ E., (2003). Studies on daylight design of high density residential housing in Hong Kong, International Journal of Lighting Research and Technology 35, 127-140.

Ng E., (2009). Designing for Daylight, in: E. Ng (Ed.), Designing High-Density Cities For Social and Environmental Sustainability, Earthscan, London; Sterling, VA.

Oke, T.R. (1981). Canyon geometry and the nocturnal urban heat island: comparison of scale model and field observations, Journal of Climatology, 1, pp. 237-254.

Oke, T.R. (1988). Street design and urban canopy layer climate, Energy and Buildings, 11, pp. 103-113.

Philipp, R., et al. (2014). Cities and Energy - Urban morphology and Heat Energy Demand. London School of Economic; European Institute for Energy Research final report, pp. 1/10 - 1/11.

Ratti, C., Raydan, D., \& Steemers, K. (2003). 'Building form and environmental performance: archetypes, analysis and an arid climate', Energy and Buildings, 35, pp. 49-59.

Robinson, D., \& Stone, A. (2004). Irradiation modelling made simple: the cumulative sky approach and its applications. Paper presented at The 21st Conference on Passive and Low Energy Architecture (PLEA), Eindhoven, The Netherlands.

Svensson, M.K. (2004), 'Sky view factor analysis: Implications for urban air temperature differences', Meteorological Applications, 11, pp. 201-211.

Vale, B., Vale, R. (2010). Is the High-Density City the Only Option? In E. Ng (Ed.), Designing High Density Cities for Social and Environmental Sustainability (pp. 19-26): Earthscan, UK and USA

Wang, P.Y. (2016). 光环境舒适度视角下寒地住区公共空间优化策略研究一一天津市既有住区为例. (博士), 天津大学建筑学院, 天津

World Business Council for Sustainable Development (WBCSD) (2009). Energy Efficiency in Buildings: Transforming the Market. Retrieved Feb 14, 2019, from https://docs.wbcsd.org/2009/08/EEBTransformingTheMarket.pdf.

Zhang, J., Heng, C. K., Hii, D. J. C., Janssen, P., Malone-Lee, L. C., \& Tan, B. K. (2010). Evaluating the Environmental Implications of Density: A Comparative case study on the relationship between density, urban block typology and sky view factor performance. Paper presented at the FUTURE CITIES: 28th eCAADe Conference, ETH, Zurich, Switzerland.

Zhang, J., Heng, C. K., Malone-Lee, L. C., Janseen, P., Hii, D. J. C., \& Ibrahim, N. (2012a). Preliminary Evaluation of a Daylight Performance Indicator for Urban Analysis: Façade Vertical Daylight Factor per Unit Floor Area. Paper presented at the SimBuild Madison, Wisconsin, USA. htpp://www.ibpsa.us/simbuild2012/Papers/SB12_TS110a_4_Zhang.pdf

Zhang, Ji, Heng, C. K., Malone-Lee, L. C., Hii, D. J. C., Janssen, P., Leung, K. S., \& Tan, B. K. (2012b). Evaluating environmental implications of density: A comparative case study on the relationship between density, urban block typology and sky exposure. Automation in Construction, 22(0), 90-101. doi:10.1016/j.autcon.2011.06.011.

Zhang, Ji (2013). A Study of the Relationship between Urban Form and Environmental Performance for Three Urban Block Typologies in Paris. Paper accepted by the SimAUD 2013 conference, San Diego, CA, USA. 